\title{
Manufacturing Ultra High Performance Concretes by Silica Fume, Ultra Fine Fly Ash and Metakaolin Addition
}

\author{
Tony Song, Ion Dumitru and Bob Bornstein \\ Boral Construction Materials, Australia
}

\begin{abstract}
SF (silica fume) has been widely used in high performance concrete manufacturing due to its pozzolanic reactivity and the filler effect of ultra-fine particles. Recently ultra-fine grades of fly ash and metakaolin have been assessed and compared with SF concretes. This paper evaluates four commercially available products in manufacturing high performance concrete, including two SF (control I and II), one ultra-fine fly ash and one ultra-fine metakaolin. The study firstly assessed the properties of each raw material, including the loss of ignition, particle size distribution, relative water demand, relative strength, available alkali, and pozzolanic index. Concrete trial mixes were further carried out to assess the concrete properties, including workability by slump, compressive strength development up to 91 days, drying shrinkage up to 91 days, durability in terms of sorptivity and rapid chloride migration coefficient tests NT 492. The study has concluded that at a given workability (slump of $200 \mathrm{~mm}$ ), the concrete with ultra fine fly ash required about $15-25 \mathrm{~kg} / \mathrm{m}^{3}$ less water, and achieved about 5-20 MPa higher compressive strength in 91 days, depending on the type of the SF used as the control. The sorptivity and chloride migration coefficient data show that concrete with ultra fine fly ash can achieve similar durability properties with SF used as control. The concrete with ultra-fine metakaolin requires similar water to control I and about $9 \mathrm{~kg} / \mathrm{m}^{3}$ more water than control II. The ultra-fine metakaolin concrete develops higher strength than control I, with similar compressive strength when compared to control II mix. This concrete mix has the lowest drying shrinkage than both controls and ultra-fine fly ash concretes. In terms of durability properties (sorptivity and chloride diffusion tests), concrete with ultra-fine metakaolin showed the best performance, especially at early age (i.e. 28 days). Therefore, it is possible to manufacture high performance concrete with ultra-fine fly ash or ultra-fine metakaolin to replace SF.
\end{abstract}

Key words: SF, ultra-fine fly ash, ultra-fine metakaolin, high performance concrete.

\section{Introduction}

SF (silica fume) has been widely used in high performance concrete manufacturing because its high amount of amorphous silica content, together with an extremely small particles size, offers increased ultimate compressive strength, reduced permeability and improved durability properties. However, SF normally has a higher water demand or higher dosage of superplasticiser for a given workability is required. It also exhibits different placement and finishing features in comparison with conventional binder concretes.

Fly ash is another widely used pozzolan in concrete. The UFFA (ultra-fine fly ash) manufactured by a

Corresponding author: Ion Dumitru, bachelor in science, technical manager, research fields: materials science and concrete technology. selective classification method can greatly improve the performance of concrete due to the shape effect, pozzolanic reactivity and the micro-aggregate effect [1-3].

The use of metakaolin as partial replacement of cement in concrete is increasing due to its high pozzolanic reactivity. The UFMK (ultra-fine metakaolin) has a very fine particle size and a narrow particle size distribution, which has the advantage in high performance concrete manufacturing.

This paper presents the experimental results when UFFA and UFMK are used to alternatively replace SF in high performance concrete.

\section{Materials and Procedures}

\subsection{Binders}

OPC (ordinary Portland cement), about $480 \mathrm{~kg} / \mathrm{m}^{3}$, 
was used for concretes assessment.

Two kinds of commercially available SF were selected as controls. SF I is a standard grade while SF II has the high quality grade. The particle size distribution of SF II is presented in Table 1. The SF addition was about $40 \mathrm{~kg} / \mathrm{m}^{3}$, or $8 \%$ of the total binder $\mathrm{OPC}+\mathrm{SF}$.

UFFA had an average diameter of 25 micrometers with $50 \%$ by volume passing 2.1 micrometers. UFMK is very fine as well with the average diameter 7.3 micrometers and $50 \%$ passing 4.7 micrometers. So, in terms of $50 \%$ passing, both UFFA and UFMK are finer than SF, but in terms of the average particle diameter, UFFA is coarser and UFMK is finer than SF. For trial mixes assessment, the addition was also $40 \mathrm{~kg} / \mathrm{m}^{3}$, or $8 \%$ of the total binder OPC + UFFA or $\mathrm{OPC}+\mathrm{UFMK}$.

\subsection{Aggregates}

Two natural sands, Nepean coarse sand and Kurnell fine sand, have been used at about $570 \mathrm{~kg} / \mathrm{m}^{3}$. These two sands have been widely used for years in the Sydney market for concrete manufacturing. CRG (crushed river gravels), $20 \mathrm{~mm}$ and $10 \mathrm{~mm}$ were used at about $1,100 \mathrm{~kg} / \mathrm{m}^{3}$. All aggregates comply with Australian Standard AS 2758.1, aggregates and rock for engineering purposes, concrete aggregates.

\subsection{Admixtures}

Three Sika admixtures, Retarder, normal range water reducer, and superplasticiser, were used. The dosage of each admixture was fixed to avoid any impact due to the admixtures. The Retarder and water reducer were added at 400 and $100 \mathrm{ml}$ per $100 \mathrm{~kg}$ binder, respectively. The superplasticiser was added at about $1,200 \mathrm{ml} / \mathrm{m}^{3}$.

\subsection{Testing SF, UFFA and UFMK}

All SF, UFFA and UFMK were tested preliminarily as per Australian Standard AS 3583 - methods of test for supplementary cementitious materials for use with Portland and blended cement. The test includes moisture content, loss on ignition, available alkali, chloride, sulphate as $\mathrm{SO}_{3}$, relative density, relative water demand and relative strength. In addition, using the PsP particle \& Surface device, the BET surface area data were also performed. The particle size distribution was determined by the MASTERSIZER 2000 device.

\subsection{Testing Concrete Properties}

A typical high strength concrete mix design was used, including $480 \mathrm{~kg} / \mathrm{m}^{3}$ OPC cement, $40 \mathrm{~kg} / \mathrm{m}^{3} \mathrm{SF}$ or UFFA or UFMK, $1,110 \mathrm{~kg} / \mathrm{m}^{3}$ coarse CRG aggregates, $570 \mathrm{~kg} / \mathrm{m}^{3}$ natural river sand. The content of OPC cement, SF and UFFA was air dry weight while all aggregates were saturated surface dry weight. Tap water was adjusted for the targeted slump of $200 \mathrm{~mm}$.

All concrete trials were carried out at laboratory conditions of $23 \pm 2{ }^{\circ} \mathrm{C}$ and $50 \% \pm 5 \%$ relative humidity, as per the following AS (Australian Standard), RMS (Roads \& Maritime Services) and NT Build (NT) standards, for fresh and hardened concrete properties, and durability performance assessment.

AS 1012.2 - prepare concrete mix in a laboratory,

AS 1012.3.1-slump test for consistency,

AS 1012.4.2 - air content of fresh concrete,

AS 1012.5-plastic density of fresh concrete,

AS 1012.8.1-wet curing of concrete for compressive strength,

AS 1012.9 - compressive strength test of hardened concrete up to 91 days,

Table 1 Particle size distribution of SF, UFFA and UFMK (micrometer).

\begin{tabular}{lllll}
\hline Samples & $\mathrm{D}(0.1)$ & $\mathrm{D}(0.5)$ & $\mathrm{D}(0.9)$ & $\mathrm{D}(\mathrm{mean})$ \\
\hline SF in control II & 2.0 & 8.2 & 23.1 & 10.7 \\
Ultra fine fly ash UFFA & 0.7 & 2.1 & 52.2 & 25.0 \\
Ultra fine metakaolin UFMK & 1.3 & 4.7 & 16.8 & 7.3 \\
\hline
\end{tabular}


AS 1012.13 - free drying shrinkage of concrete up to 91 days,

RMS T362 - interim test for verification of curing regime-sorptivity,

NT Build 492 - chloride migration coefficient from non-steady state migration experiments of concrete, mortar and cement based repair materials.

\section{Results and Discussion}

\subsection{Chemical and Physical Properties of SF, UFFA} and $U F M K$

The trial mixes results are presented in Table 2 .

For the purpose of comparison, two types of SF were selected. Both have very high $\mathrm{SiO}_{2}$ content, above 97\%, and similar BET surface area, over 21 $\mathrm{m}^{2} / \mathrm{g}$. As expected, the SF required more water for the same workability. SF II had better relative strength, more than $100 \%$, while SF I achieved slightly lower compressive strength than $100 \%$. Therefore, these two SF samples would be representative as two different scenarios of SF.

By contrast, the UFFA sample has lower water demand (i.e. 98\%) and a fairly high relative strength (i.e. $145 \%$ compared to only $115 \%$ by SF II). This makes the UFFA a possible binder to replace SF for manufacturing high performance concrete.

The UFMK has similar water demand to SF I and about $4 \%$ higher than SF II. However, the relative strength is almost $30 \%$ higher than SF I and about $10 \%$ higher than SF II, even though it does not show as good as UFFA performance. Considering the fine particle size of UFMK (Table 1) and relatively high reactivity, UFMK showed positive results to be used in the high performance concrete as well.

\subsection{Workability}

The total water content is given in Table 3. As expected, fly ash generally reduces water demand because of the spherical shape and bearing effect. For a given slump of $200 \mathrm{~mm}$, concrete with UFFA reduced the water demand with approximately 25 $\mathrm{kg} / \mathrm{m}^{3}$ and $15 \mathrm{~kg} / \mathrm{m}^{3}$ when comparing to concretes with SF I and SF II, respectively. The water demand of the UFMK mix is similar to SF I but about $9 \mathrm{~kg} / \mathrm{m}^{3}$ higher than SF II. This agrees with the trend of water demand by testing mortar samples (Table 2). Also, the concrete with UFFA was not as sticky as control concrete mixes.

It is commonly considered that the use of a fine powder will increase the water demand due to the increment of surface area. This was well reflected in two control mixes with SF and UFMK. The less water demand and good workability of the UFFA mix is probably explained as follows: (a) the particle size of UFFA is indeed finer than the normal fly ash, but it is still not as fine as SF; (b) the UFFA spherical particles can easily roll over one another, reducing interparticle friction; (c) the use of UFFA also broadens the particle size distribution of the overall cementitious system, thus potentially improving packing features

Table 2 Testing SF, UFFA and UFMK.

\begin{tabular}{lllll}
\hline Samples & SF I & SF II & UFFA & UFMK \\
\hline Loss on ignition \% AS 3583.3 & 5.3 & 1.1 & 0.3 & 0.8 \\
Relative density AS 3583.5 & 2.07 & 2.19 & 2.58 & 2.47 \\
Relative water requirement \% AS 3583.6 & 111 & 115 & 98 & 111 \\
Relative strength 7 days (accelerated) AS 3583.6 & 95 & 115 & 145 & 126 \\
Relative strength 28 days (standard) AS 3583.6 & 88 & 104 & 128 & 114 \\
Silicon as $\mathrm{SiO}_{2} \%$ Boral ICP method & 97.7 & 97.2 & 57.1 & 53.8 \\
Chloride as $\mathrm{Cl}_{\text {\% AS 3583.13 }}$ & 0.037 & 0.004 & 0.004 & 0.001 \\
Sulphate as $\mathrm{SO}_{3} \%$ AS 3583.8 & 0.4 & 0.5 & $<0.1$ & 0.1 \\
Available alkali\% AS 3583.12 & $<0.1$ & $<0.1$ & 0.2 & $<0.1$ \\
BET surface area m 2 /g & 21.6 & 22.3 & 4.30 & 11.45 \\
\hline
\end{tabular}



Ultra Fine Fly Ash and Metakaolin Addition

Table 3 Binder content and water demand of concrete trials (after yield correction).

\begin{tabular}{lllll}
\hline Materials & Control SF I & Control SF II & With UFFA & With UFMK \\
\hline OPC cement $\left(\mathrm{kg} / \mathrm{m}^{3}\right)$ & 474 & 478 & 482 & 472 \\
SF/UFFA/UFMK $\left(\mathrm{kg} / \mathrm{m}^{3}\right)$ & 41 & 42 & 42 & 41 \\
Total water $\left(\mathrm{kg} / \mathrm{m}^{3}\right)$ & 196.1 & 186.2 & 170.7 & 195.4 \\
Slump AS $1012.3 .1(\mathrm{~mm})$ & 200 & 200 & 200 & 200 \\
Fresh concrete density AS $1012.5\left(\mathrm{~kg} / \mathrm{m}^{3}\right)$ & 2,371 & 2,377 & 2,380 & 2,362 \\
Air content AS $1012.4 .2(\%)$ & 2.1 & 2.1 & 2.1 & 2.3 \\
\hline
\end{tabular}

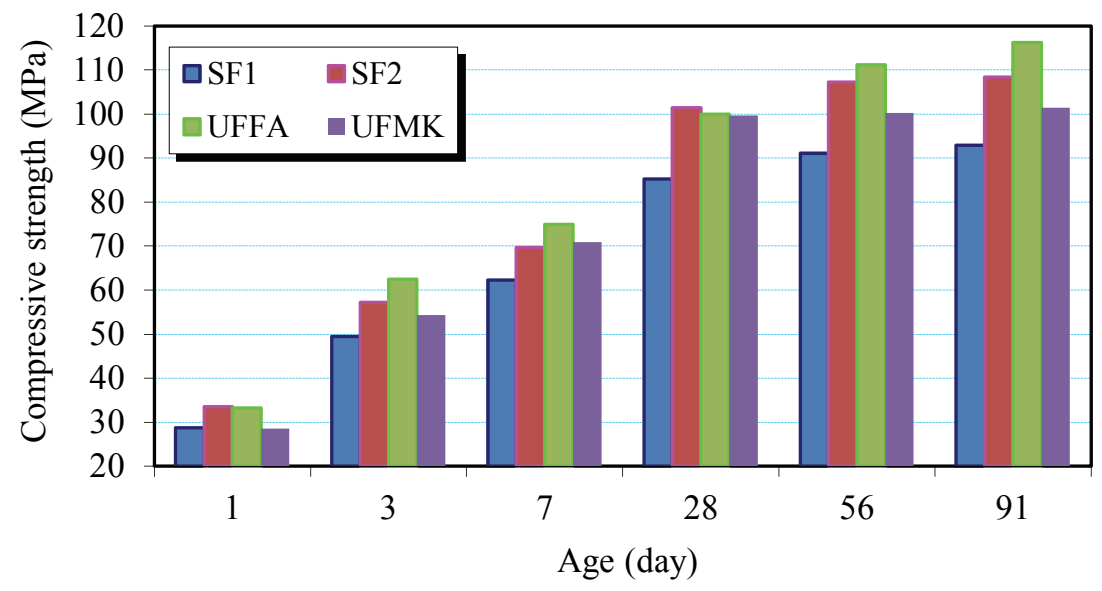

Fig. 1 Compressive strength development over ages.

which would result in an increased availability of free water, leading to improved workability [2]; (d) the higher proportion of submicron particles in the UFFA may probably adsorb on the surface of the cement grains and prevent flocculation, thus, reducing water demand [4]. No matter what this exact mechanism is, the concrete testing results hereby clearly show the less water demand of UFFA for a given workability.

\subsection{Compressive Strength}

The results of compressive strength are presented in Fig. 1.

It is clear that the UFFA concrete has achieved about $20-25 \%$ higher compressive strength than the control 1 - concrete with SF I at all ages. The UFFA concrete had achieved similar strength to the control 2 -concrete with SF II till 28 days, and exceeded about 5-8 $\mathrm{MPa}$ at 56 and 91 days.

The UFFA resulted in very substantial strength gain at early age, i.e. $33.3 \mathrm{MPa}$ at day 1 , similar to 33.6 MPa of concrete with SF II. This would mark UFFA suitable for higher early strength application in precast factories. The UFFA is able to continue strength development at later age, similar to the trend of typical class F fly ash characteristics in concrete.

The good performance of UFFA concrete in terms of compressive strength is derived from three main characteristics, the spherical shape, finer particles and reactivity through the chemical composition. As seen in Table 1 , about $50 \%$ by volume of UFFA has its particles less than 2.1 micrometers. These very fine particles would prove the "ball bearing effect" which assists in reducing water demand and a lower water/cement ratio is always favorable for high strength concrete. On the other hand, these very fine particles could efficiently fill the voids between cement grains and other fine particles in concrete to improve particle packing, which actively improves strength gain characteristics. In addition, these very fine particles would enhance its pozzolanic reactivity.

It was noted that concrete with UFMK has similar strength gain as SF I, about 28.5 $\mathrm{MPa}$ at day 1 , but 
exceeded SF I strength after 3 days and afterwards. UFMK mix has equivalent strength gain in comparison with SF II till age of 28 days. This good early age strength development of UFMK could be attributed to: (1) the cement hydration at early age was enhanced due to the reaction of UFMK and portlandite forming additional CSH (calcium-silicate-hydrate) [5], (2) good bond between the aggregate and the cement paste, (3) low porosity due to the filler effect of fine metakaolin particles packing into cement particles gaps [6].

\subsection{Drying Shrinkage}

The results of drying shrinkage were plotted in Fig. 2. The UFFA concrete had lower shrinkage than control SF I and had very similar trend to control SF II. By contrast, the UFMK concrete has the lowest drying shrinkage in the trial mix carried out.

It is well acknowledged that the water content is one of the major contribution factors to concrete drying shrinkage. As previously discussed, the spherical shape particles and the very fine particle packing actions assist in the reduction of water content of UFFA concrete. As a result, the drying shrinkage of UFFA concrete will be lower.

As showed in Table 3, even though the UFMK has similar water demand to SF I and about $9 \mathrm{~kg} / \mathrm{m}^{3}$ higher than SF II and $25 \mathrm{~kg} / \mathrm{m}^{3}$ higher than UFFA mix, the lowest drying shrinkage of UFMK concrete could be due to a combination of (1) denser pore structure; (2) stronger paste matrix; and (3) improved paste aggregate interface. The lowest drying shrinkage of UFMK and its associated benefits could be related to good concrete crack resistance.

\subsection{Sorptivity}

Sorptivity test has been carried out as per RMS T362 method. For each mix, two concrete beams 100 $\times 100 \times 350 \mathrm{~mm}$ were cast, and wet cured as per AS 1012.8.1 till age 7 days, then exposed to the drying shrinkage room conditions $\left(23 \pm 2{ }^{\circ} \mathrm{C}\right.$ and $50 \% \pm 5 \%$ $\mathrm{RH})$ for 35 days. The water penetration depth after soaking the concrete beams in water over a period of 24 hours was recorded and reported as sorptivity. This test is a compulsory test for concrete to be used for B80 application (i.e. bridge). The results of sorptivity are shown in Fig. 3.

It is noticed that the UFFA concrete had water penetration depth between two controls. However, all three types concrete meet the requirement of RMS B80 for exposure class $\mathrm{C}$ condition (i.e. maximum of $8 \mathrm{~mm}$ ). The low sorptivity results of UFFA concrete indicates that the interconnectivity of capillary pores in UFFA concrete must have been reduced to a quite lower level because of the very fine particles. It is also considered that the ongoing hydration of silica-alumina

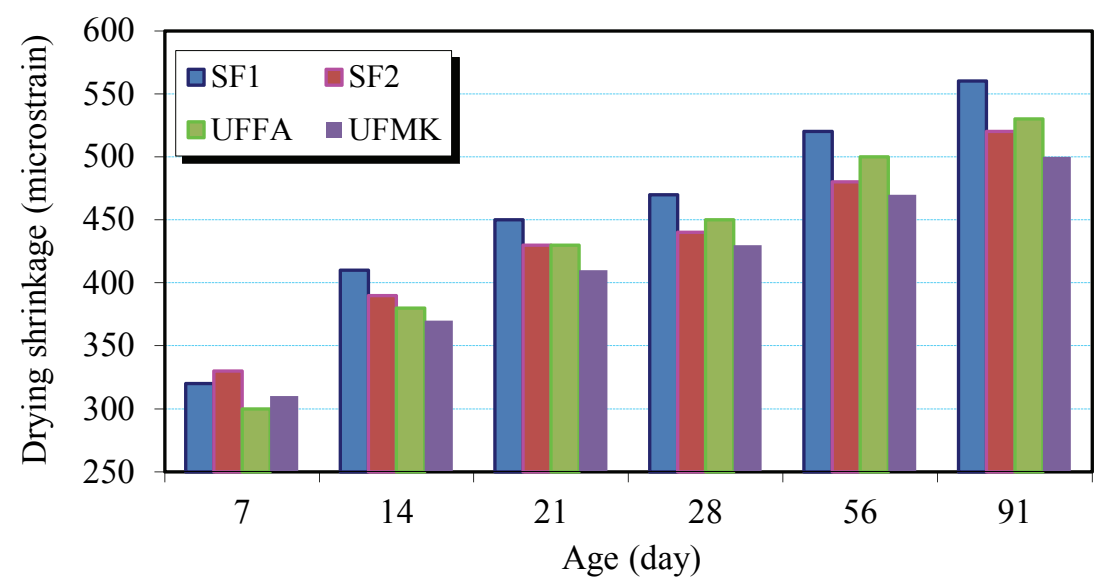

Fig. 2 Drying shrinkage development over ages. 


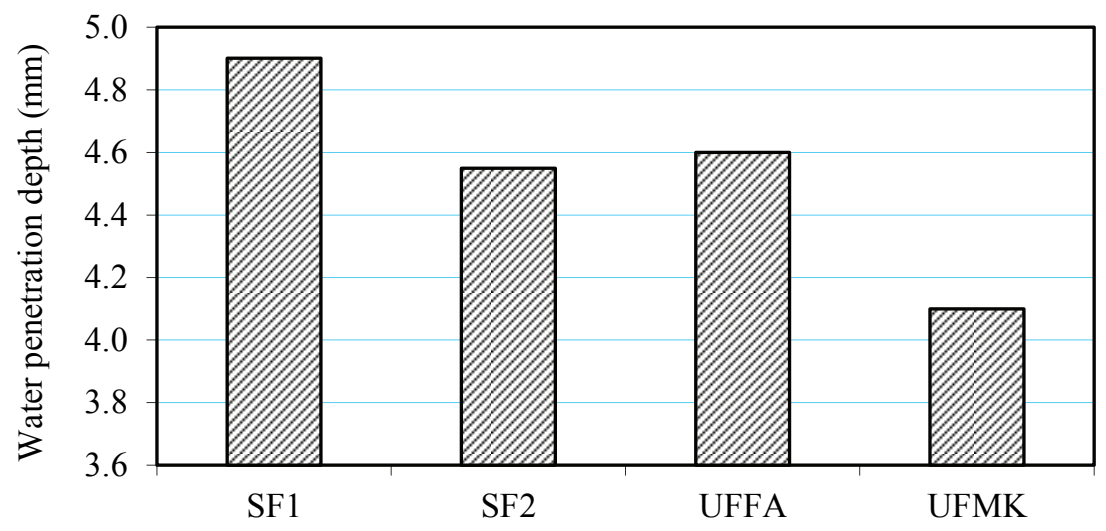

Fig. 3 Sorptivity results.

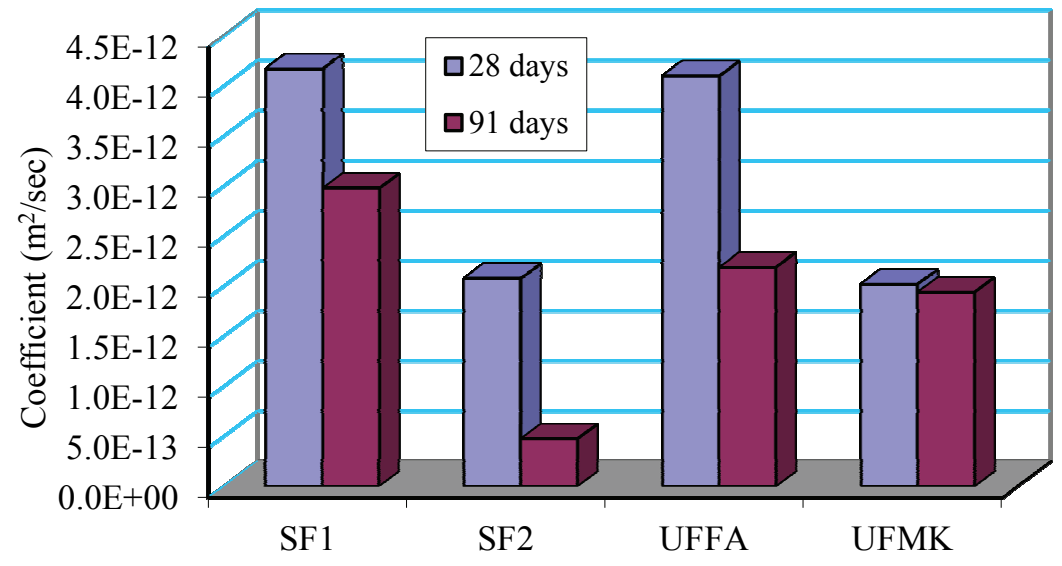

Fig. 4 NT 492 results at age of 28 and 91 days.

hydrates would make the concrete matrix even denser at later age and good durability performance is expected.

By contrast, the UFMK concrete has lowest sorptivity depth, indicating that the UFMK concrete had a decreased porosity and a refined pore size. Reduced sorptivity of UFMK would inhibit ingress of aggressive elements into concrete.

\subsection{Durability Performance by Rapid Chloride} Migration Coefficient Results

The durability performance of concrete for bridge application is assessed by either NT 492 or NT 443 tests in RMS B80 specification. Three cylinders were cast and wet cured till age of 28 days and 91 days performed as per NT 492 procedures. The results of NT 492 test are presented in Fig. 4.

As expected, the UFFA concrete had its chloride migration coefficient value between the two controls. It is noted that concrete with SF I and UFFA had just failed to meet the requirement of RMS B80 class $\mathrm{C}$ at age of 28 days, limit of $4.0 \mathrm{E}-12 \mathrm{~m}^{2} / \mathrm{sec}$. However, the chloride migration coefficient declined significantly with longer curing ages. This demonstrates the potential of UFFA concrete to reduce chloride permeability. This can be attributed to (a) very fine particles improved the inner microstructure of concrete and greatly enhanced the compactness; (b) 
pozzolanic reaction reinforced the matrix and refined the capillary pores.

Interestingly, UFMK concrete performed much better than control SF I at both ages, and similar to control SF II (good quality SF) at age of 28 days. Due to the high reactivity and fine particles of UFMK, most hydration would have completed at early age (i.e. 28 days). This probably explains why the chloride diffusion coefficient at 91 days is marginally lower than the 28 days results.

\section{Conclusions}

Based on the experiment presented above, the following conclusions should be noted.

- UFFA displays a strong tendency to reduce the water demand, in both mortar and concrete tests. With $8 \%$ addition of UFFA and for a given slump of 200 $\mathrm{mm}, 15-25 \mathrm{~kg} / \mathrm{m}^{3}$ reduction in total water was achieved. Concrete with UFFA used less water and it was less sticky in comparison with concretes with SF.

- At equal addition content (i.e. $8 \%$ of total binder), UFFA can produce concrete strengths comparable with that produced with high quality SF at early age, and the compressive strength becomes significant at a later age (i.e. up to 91 days).

- UFFA appears to provide equivalent durability performance, in terms of sorptivity and rapid chloride migration coefficient NT 492 test, for B80 class C bridge concrete application.

- UFMK acted as an accelerating mineral admixture in promoting cement hydration at early age. The UFMK concrete has equivalent compressive strength at 28 days in comparison with the high quality SF mix SF II.
- Relatively finer and higher pozzolanic metakaolin has a reduced porosity and pore size. Accordingly, the UFMK concrete mix has achieved the lowest drying shrinkage, the lowest sorptivity depth and better chloride resistance at early age of 28 days.

\section{Acknowledgments}

The authors gratefully acknowledge the support of Boral Materials Technical Services and Boral Cement and approval to publish this paper. The opinions expressed in this paper are entirely those of the authors and not necessarily the policies and practices of the organizations they represent.

\section{References}

[1] Bouzoubaa, N., Zhang, M. H., and Malhotra, V. M. 1997. "The Effect of Grinding on Physical Properties of Fly Ashes and Portland Cement Clinker." Cement and Concrete Research 27 (12): 1861-74.

[2] Obla, K. H., Hill, R. L., Thomas, M. D. A., Shashiprakash, S. G., and Perebatova, O. 2003. "Properties of Concrete Containing Ultra-fine Fly Ash." ACI Materials Journal 100 (5): 426-33.

[3] Gao, Y. L., Ma, B. G., and Zhou, S. Q. 2008. "Production and Engineering Application of C60 High Performance Pump Pebble Concrete Containing Ultra Fine Fly Ash.” Canadian Journal of Civil Engineering 35 (8): 757-63.

[4] Helmuth, R. 1987. Fly Ash in Cement and Concrete. Skokie, Illinois: Portland Cement Association. ISBN 0-89312-085-5.

[5] Mlinarik, L., and Kopecsko, K. 2013. "Impact of Metakaolin-A New Supplementary Materials - On the Hydration Mechanism of Cements." Civil Engineering \& Architecture 56 (2): 100-10.

[6] Poon, C., Kou, S., and Lam, L. 2006. "Compressive Strength, Chloride Diffusivity and Pore Structure of High Performance Metakaolin and Silica Fume Concrete." Construction and Building Materials 20: 858-65. 